\title{
Caracterização de cerâmicas sinterizadas por fluxo viscoso
}

\author{
(Phase formation of viscous flow sintered ceramics) \\ C. Gibertoni, P. I. Paulin F., M. R. Morelli
Departamento de Engenharia de Materiais, Universidade Federal de S. Carlos \\ Rod. Washington Luiz, km 235, S. Carlos, SP 13565-905 \\ morelli@power.ufscar.br
}

\begin{abstract}
Resumo
Este trabalho visou o estudo de cerâmicas sinterizadas por fluxo viscoso com ênfase na formação de fases e desenvolvimento microestrutural. Foram estudadas composições de grês porcelanato, preparadas a partir de mistura de argila plástica, caulim, feldspato, quartzo e talco: i) uma composição baseada em formulação encontrada em literatura, e ii) composições preparadas com a finalidade de se observar o efeito da adição de um formador de fase vítrea obtido em laboratório, em substituição ao feldspato. A formação de uma grande quantidade de fase líquida viscosa, durante o processo de queima do grês porcelanato a elevadas temperaturas, favoreceu a eliminação da maioria dos poros e, como conseqüência, a densificação do corpo. A adição da fase vítrea resultou em amostras com boas propriedades físicas e necessidade de menores temperaturas de queima. Portanto, é possível substituir a matéria-prima de maior custo - o feldspato - por uma fase vítrea inerte, sem comprometimento do processamento, propriedades físicas e estéticas do produto final.
\end{abstract}

Palavras-chave: grês porcelanato, fluxo viscoso.

\begin{abstract}
This work describes an investigation carried out for ceramics sintered by viscous flow with emphasis on phase formation and microstructural development. In this work, compositions prepared by mixing ball clay, kaolin, feldspar, quartz and talc were studied They consisted of a composition based on the formulation of stoneware tileand reported in the literature and compositions intentionally prepared to observe the effect of the addition of a vitreous phase former, replacing feldspar on the phase formation and final characteristics. The formation of a great amount of liquid viscous phase during the firing process of the stoneware tiles at high temperatures provided the elimination of the majority of the pores and, consequently, the densification of the body. The addition of vitreous phase former resulted in samples with good physical properties fired at relatively low temperatures. In addition, it was possible to replace a costly raw material, i.e., feldspar by an inert vitreous phase former previously obtained, without affecting the processing, physical and visual properties of the final product.
\end{abstract}

Keywords: stoneware tile, viscous flow.

\section{INTRODUÇÃO}

Dentre os diversos tipos de placas cerâmicas para revestimento produzidas mundialmente, a tipologia grês porcelanato tem se destacado, devido às suas propriedades técnicas (baixa absorção de água, alta resistência mecânica e à abrasão, elevada resistência química e ao gelo) e sua semelhança com pedras [1].

Por falta de uma definição mais precisa, pode-se definir revestimento porcelanato como um revestimento cerâmico impermeável, ou seja, sem nenhuma ou quase nenhuma porosidade aparente, esmaltado ou não, branco ou colorido pela adição de pigmentos na composição original [2].

Devido às suas características o grês porcelanato é motivo de atenção tanto de fabricantes nacionais e internacionais como também da comunidade científica, que procuram otimizar suas propriedades a fim de que, mesmo sendo constituído por matérias-primas essencialmente naturais, possa apresentar um desempenho comparável a cerâmicas técnicas, cujas tecnologias empregadas na fabricação são bem mais sofisticadas. Dessa maneira, compreender o desenvolvimento das fases presentes nesse material cerâmico é fundamental. Durante as duas últimas décadas, este produto passou por um aprimoramento tecnológico, desde a utilização de novas matérias-primas até o desenvolvimento de novos equipamentos para o processo produtivo [3]. A produção de grês porcelanato mundial tem aumentado progressivamente nos últimos dois anos. Atualmente o volume de produção de grês porcelanato na Itália já ultrapassou $50 \%$ da produção total de revestimentos cerâmicos daquele país [4]. Tal resultado seguramente se deve à pesquisa aplicada que, a partir de um produto tradicional para aplicações usuais na pavimentação, foi capaz de propor um produto inovador, diversificado e versátil que apresenta as características fundamentais necessárias para conquistar e manter uma posição de destaque no mercado. $\mathrm{O}$ grês porcelanato é um produto capaz de equilibrar a relação custo produtivo/ faturamento com um volume produzido muito menor que os produtos de monoqueima convencionais e, por apresentar grande aceitação no mercado externo, a produção nacional deste produto deve apresentar um rápido crescimento. Estudos apontam para uma provável insuficiência do setor 
mineiro em atender a demanda por fundentes, dado o período de maturação dos investimentos necessários, sendo previsto um aumento no volume de importação do feldspato [5].

Um ponto de importância neste trabalho é o estudo da sinterização por fluxo viscoso. O feldspato, que se decompõe por meio de reação peritética e origina a fase líquida, propicia uma sinterização por meio da formação de um líquido reativo. Na substituição dessa matéria-prima por uma fase vítrea pré-obtida, há o surgimento de fluxo viscoso, comumente observado durante a queima de vidrados $\mathrm{e}$ vidros. Um melhor entendimento desse mecanismo de sinterização tem sua importância por estar presente na fabricação de cerâmicas vitrificadas e semi-vitrificadas, tais como cerâmicas de revestimento, cujo maior representante é o grês porcelanato. $\mathrm{O}$ acompanhamento da formação de fases a partir da transformação de cada matéria-prima, durante a etapa de queima do grês porcelanato, aliado à observação da influência da fase vítrea (sinterização por fluxo viscoso) poderá contribuir para a possibilidade de substituição de matérias-primas fundentes do tipo feldspato por outras fontes de álcalis.

\section{PROCEDIMENTO EXPERIMENTAL}

Para o desenvolvimento experimental desse trabalho, foram utilizadas as seguintes matérias-primas apresentadas na Tabela I.

\section{Composições}

As composições foram formuladas baseadas em uma composição teórica $(45 \%$ - Feldspato, $30 \%$ - Argila São Simão, $15 \%$ - Caulim, 7\% - Quartzo e 3\% - Talco) onde foram feitas, essencialmente, modificações, sempre nas quantidades em peso, das matérias-primas: i) fluxo e ii) feldspato.

As composições estudadas foram denominadas da seguinte forma:

- Teórica contendo: $45 \%$ - Feldspato, $30 \%$ - Argila São Simão, 15\% - Caulim, 7\% - Quartzo e 3\% - Talco;

Tabela I - Análise química das matérias-primas (\% em peso). [Table I - Chemical analysis of raw materials (wt. \%).]

\begin{tabular}{cccc}
\hline Amostra & $\mathrm{SiO}_{2}$ & $\mathrm{Al}_{2} \mathrm{O}_{3}$ & Álcalis * \\
\hline Feldspato & & & \\
Potássico $^{(1)}$ & 65,92 & 19,31 & 14,77 \\
Caulim $^{(1)}$ & 52,74 & 45,83 & 1,44 \\
Argila São Simão $^{(1)}$ & 63,76 & 35,03 & 1,21 \\
Quartzo $^{(1)}$ & 99,23 & 0,50 & 0,27 \\
Fluxo $^{(2)}$ & 73,40 & 1,79 & 24,81 \\
Talco $^{(3)}$ & 66,58 & 0,62 & 32,80 \\
\hline
\end{tabular}

* teores de $\mathrm{CaO}+\mathrm{Na}_{2} \mathrm{O}+\mathrm{K}_{2} \mathrm{O}+\mathrm{MgO}$; origem das matérias-primas: (1) MINASOLO Comércio e Representação Ltda., (2)UFSCar, ${ }^{(3)}$ TALMAG PP-325 - Magnesita S.A.
- 50\% Fluxo - 50\% Feldspato contendo: 22,5\% Feldspato, 22,5\% - Fluxo, 30\% - Argila São Simão, 15\% - Caulim, 7\% - Quartzo e 3\% - Talco;

- NF contendo: 30\% - Fluxo, 38\% - Argila São Simão, 19\% - Caulim, 9\% - Quartzo, 4\% - Talco.

\section{Preparação das Composições}

A fase vítrea previamente formada foi obtida pela mistura de óxidos de silício, cálcio e sódio (grau industrial), por meio de fusão a $1300{ }^{\circ} \mathrm{C}$ e posterior etapa de resfriamento ao ar. Após essa etapa, foi cominuída para se obter a granulometria máxima correspondente à malha 325 mesh $(44 \mu \mathrm{m})$.

Cada composição, com o teor de água calculado, a fim de se ter uma densidade de $1,65 \mathrm{~g} / \mathrm{cm}^{3}$ (em torno de $60 \%$ em peso de sólidos), com a adição de $0,25 \%$ de silicato de sódio (defloculante), foi homogeneizada por 8 horas, em um moinho de bolas (relação em peso 4:1 bolas-material).

A barbotina de cada composição foi atomizada (granulação da massa) em "spray dryer" (Niro Atomizer - Copenhagen, Denmark) de escala semi-industrial, mantendo-se a pressão na faixa 1,7-2,0 bar e temperatura na faixa $70-115^{\circ} \mathrm{C}$. A umidade desejada do pó foi de $8 \%$. O pó atomizado foi armazenado durante um período mínimo de $48 \mathrm{~h}$ para a homogeneização da umidade.

\section{Conformação e queima dos corpos de prova}

A conformação dos corpos de prova foi realizada por meio de prensagem uniaxial, em prensa hidráulica, utilizando um molde metálico rígido. Foi aplicada uma pressão de compactação em torno de $350 \mathrm{Kgf} / \mathrm{cm}^{2}$.

$\mathrm{O}$ ciclo de queima utilizado foi: taxa de aquecimento igual a $10^{\circ} \mathrm{C} / \mathrm{min}, 15 \mathrm{~min}$ de permanência na temperatura de queima (variando de 650 a $1250{ }^{\circ} \mathrm{C}$ ) e resfriamento natural até temperatura ambiente. $\mathrm{O}$ objetivo foi acompanhar as transformações e formação de fases da composição de grês porcelanato padrão.

O mesmo procedimento, utilizado para a composição teórica, foi aplicado a composição nova de grês porcelanato, denominada 50\% Fluxo - 50\% Feldspato onde a matériaprima fundente (feldspato) foi substituída parcialmente pela fase vítrea previamente obtida (fluxo), e também para a composição NF onde o teor do fundente, com a substituição total do feldspato, foi reduzido mantendo-se a proporção entre todas as matérias-primas relativas à composição teórica.

\section{Caracterização das amostras queimadas}

As amostras queimadas foram caracterizadas quanto à resistência mecânica à flexão (em equipamento Hausfiled Tensometer, com escalas de 30, 60 e $120 \mathrm{Kgf}$, com erros na leitura de $\pm 0,1, \pm 0,5$ e $\pm 1,0 \mathrm{Kgf}$, respectivamente), absorção de água e retração linear de queima, difração de raios $\mathrm{X}$ 
(difratômetro Siemens - modelo D5000, faixa de $2 \theta$ de $10^{\circ}$ a $80^{\circ}$, modo contínuo a $2 \mathrm{grau} / \mathrm{min}$ ). As características cerâmicas foram determinadas para as composições de grês porcelanato padrão (composição teórica) e reformuladas (com adição de fase vítrea previamente formada) após cada tratamento térmico.

\section{RESULTADOS E DISCUSSÃO}

A Fig. 1 apresenta as curvas de gresificação obtidas por meio da caracterização de cada composição estudada: teórica, substituição parcial (50\% Fluxo - 50\% Feldspato) e substituição total (NF) do feldspato pela fase vítrea previamente obtida (fluxo).

Segundo os resultados obtidos contidos nas curvas apresentadas (Fig. 1), pode-se observar uma maior gresificação do material quando da substituição do feldspato pela matéria-prima fluxo, a temperaturas de queima mais baixas. Essa maior gresificação é entendida como uma menor percentagem de absorção de água em função das temperaturas de queima, conforme o corpo se contrai. Isso pode ser explicado devido à formação de uma maior quantidade de fase líquida viscosa pela presença da matéria-prima fluxo, provocando uma redução mais efetiva na porosidade. Vale lembrar que um produto é considerado como grês porcelanato, quando a absorção de água não ultrapassa o valor de $0,5 \%$ (Norma ISO 13006).

Foi determinada, para as três composições estudadas, a resistência mecânica à flexão, por meio da determinação da carga de ruptura e do módulo de resistência à flexão. Os resultados, em função da temperatura, são mostrados na Fig. 2.

Com respeito à carga de ruptura e ao módulo de resistência à flexão, todas as composições apresentam valores compatíveis aos exigidos pelas normas específicas à classe de absorção de água (para o grupo BIa - absorção de água inferior a $0,5 \%$ : carga de ruptura deve ser superior a $700 \mathrm{~N}$ e módulo de resistência à flexão deve ser superior a $35 \mathrm{MPa}$, segundo a norma NBR 13818/1997). Os valores de módulo de ruptura satisfizeram à norma a partir de temperaturas de queima na faixa de $925^{\circ} \mathrm{C}$, para a composição $\mathrm{NF}$ e, em torno de $1075^{\circ} \mathrm{C}$, para as demais composições. Como pode ser observado na Fig. 2b, a composição NF apresentou valores de módulo de resistência à flexão muito superiores aos apresentados pelas outras composições.

Na Fig. 3, são apresentados os difratogramas obtidos para as três composições estudadas, além do difratograma de uma amostra de um produto industrializado (comercial).

Na Fig. 4 são mostradas as micrografias obtidas por microscopia eletrônica de varredura (MEV) para as três composições em estudo e para o produto industrializado. Todas as micrografias apresentadas mostram detalhes da microestrutura observada (com aumentos variando de 5000 a 16000 vezes).
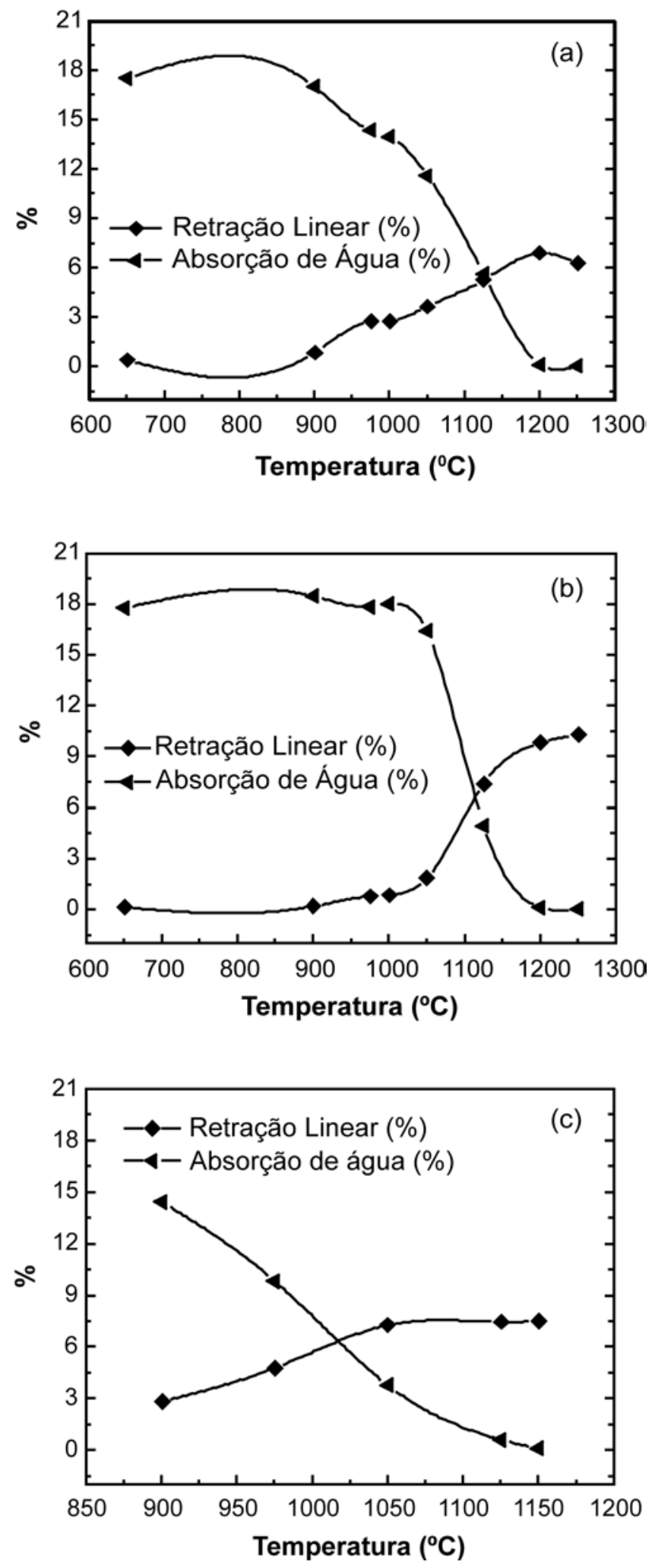

Figura 1: Curvas de gresificação para (a) composição teórica, (b) composição 50\% fluxo-50\% feldspato e (c) composição NF.

[Figure 1: Vitrification diagram (a) composition based in literature, (b) composition 50\% flux-50\% feldspar and (c) composition NF.] 

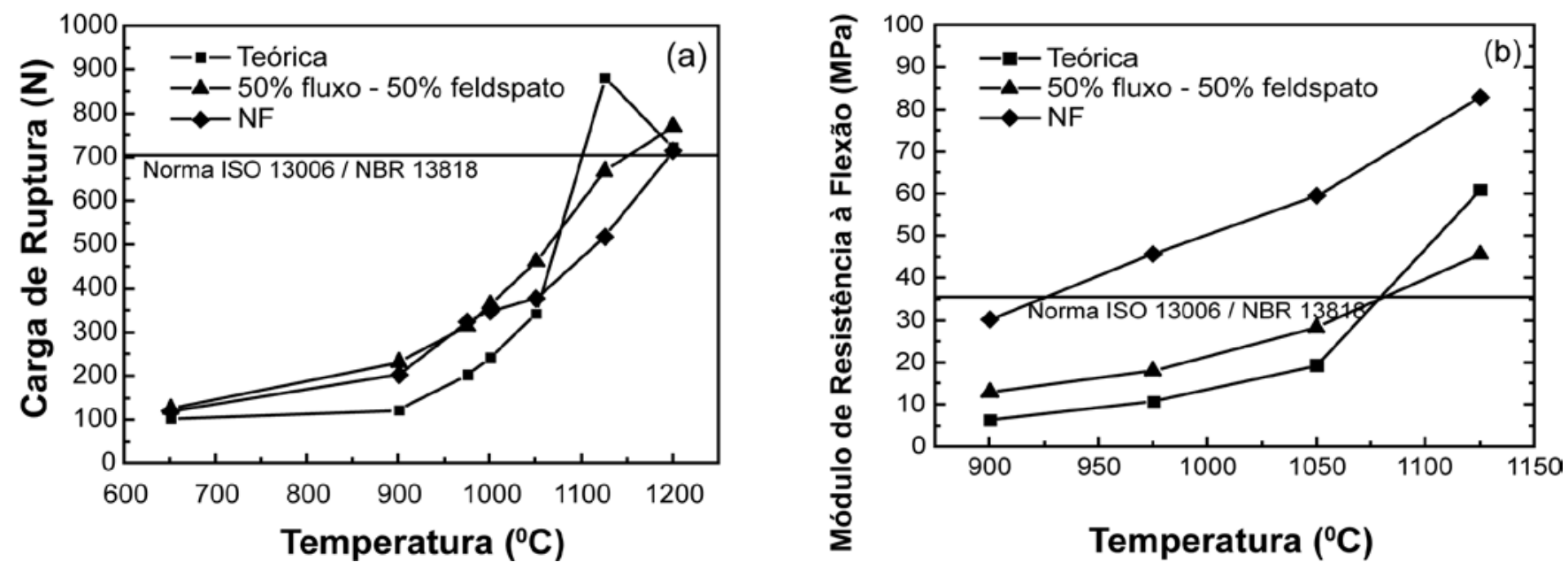

Figura 2: Variação da (a) carga de ruptura e (b) módulo de resistência à flexão em função da temperatura de queima. [Figure 2: Variation of: (a) breaking load and (b) module of rupture as a function of the firing temperature.]
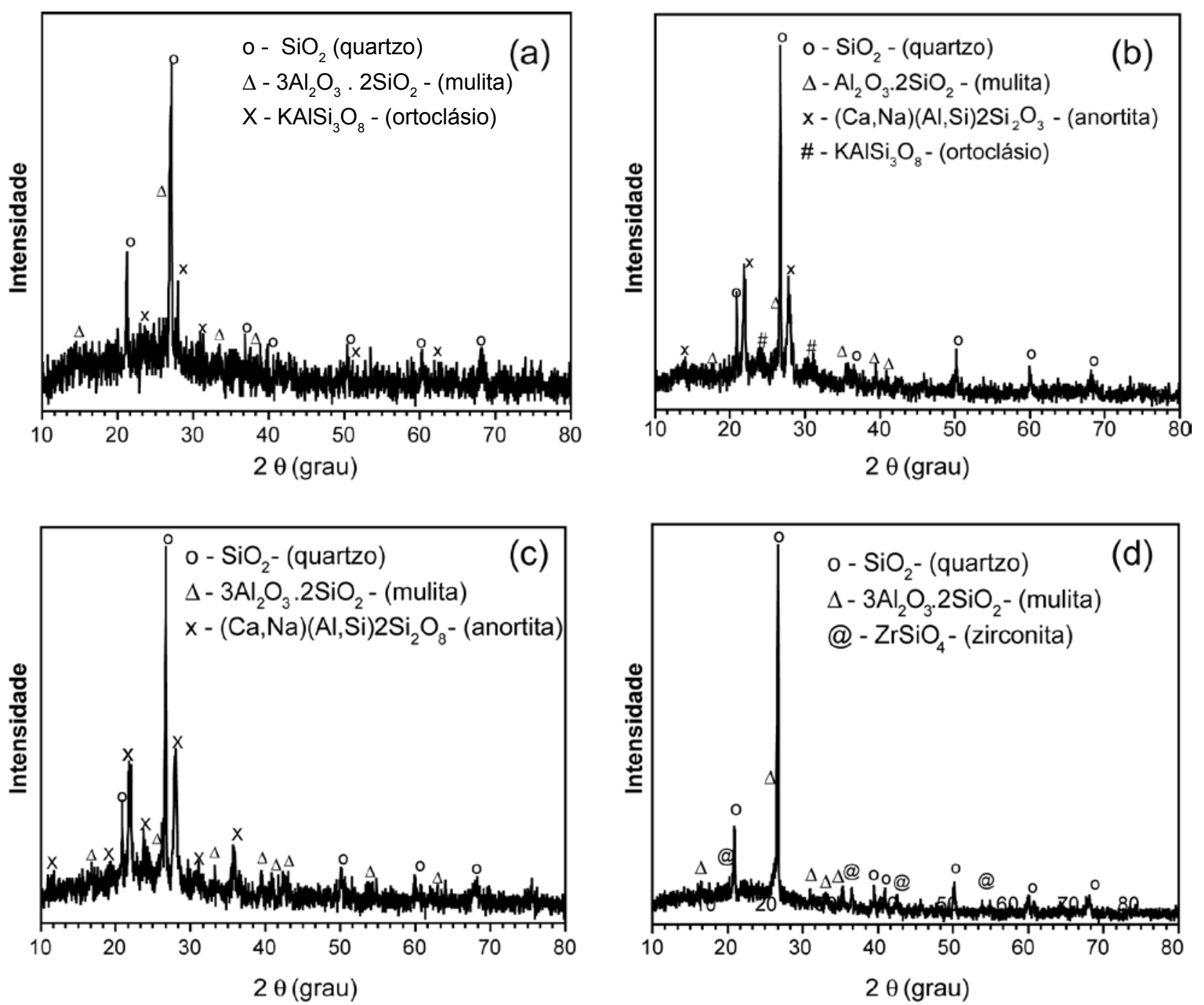

Figura 3: Difratogramas de raios X: (a) composição teórica, (b) composição $50 \%$ fluxo $-50 \%$ feldspato, (c) composição NF e (d) produto industrializado. [Figure 3:XRD patterns: (a) composition based in literature, (b) composition 50\% flux-50\% feldspar, (c) composition NF and (d) commercial product.] 

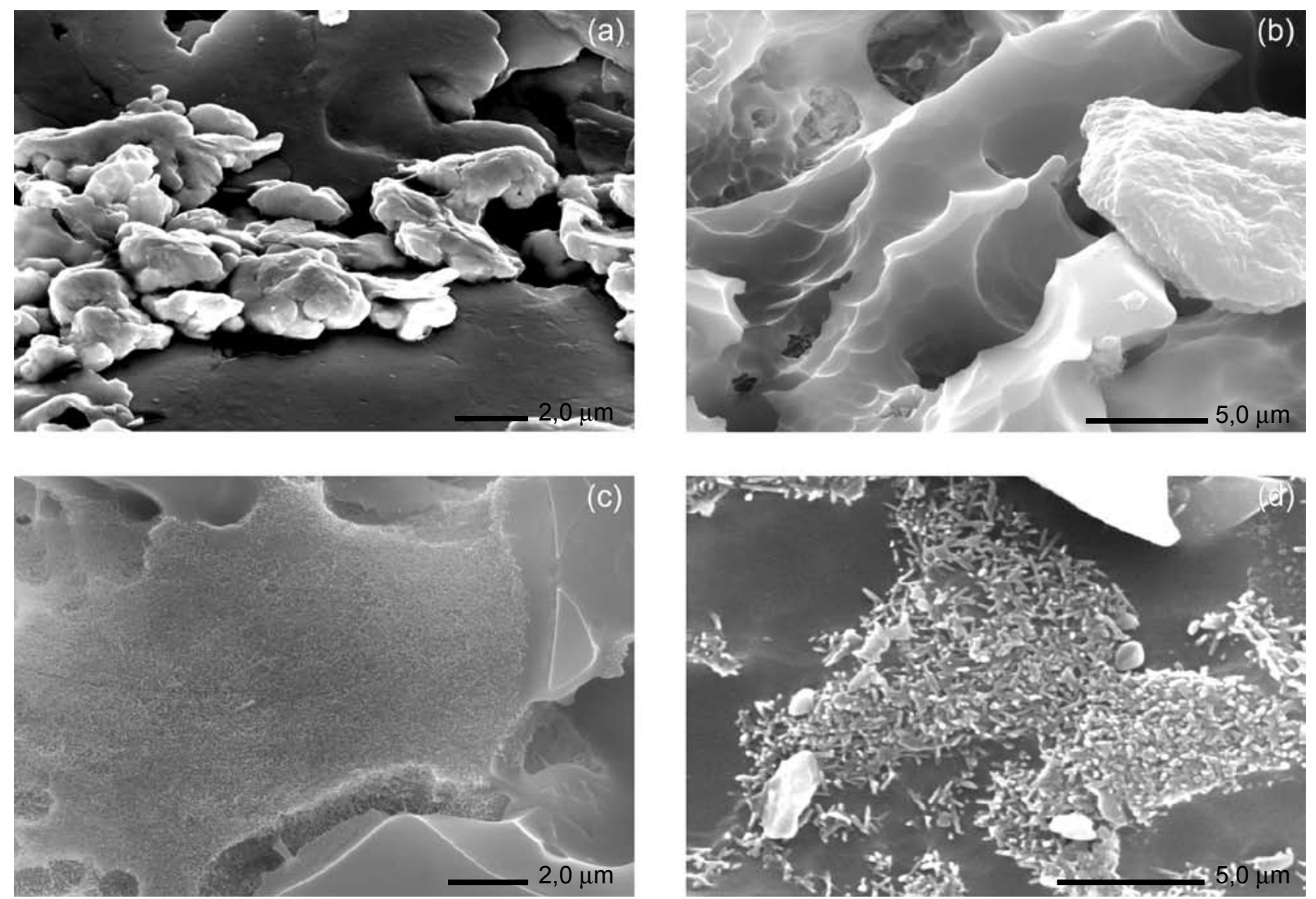

Figura 4: Micrografias obtidas em microscópio eletrônico de varredura das amostras (a) composição teórica, (b) composição 50\% fluxo $-50 \%$ feldspato, (c) composição NF e (d) produto industrializado.

[Figure 4: Scanning electron microscopy micrographs of samples: (a) composition based in literature, (b) composition 50\% flux - 50\% feldspar), (c) composition NF and (d) commercial product.]

Quanto aos resultados obtidos por meio do ensaio de difração de raios X (Fig. 3), podemos observar a fase cristalina quartzo e mulita em todas as amostras analisadas.

As micrografias apresentadas na Fig. 4 mostram detalhes da microestrutura de cada composição estudada. Na Fig. 4aépossível observar a presença de feldspato remanescente detectado pela análise de raios X. A Fig. 4b apresenta grãos de quartzo e as Figs. $4 \mathrm{c}$ e $4 \mathrm{~d}$ mostram a presença da fase mulita nucleada (na forma de pequenas agulhas) e uma grande quantidade de fase vítrea.

\section{CONCLUSÕES}

Pelos resultados obtidos, a substituição da matéria-prima natural fundente (feldspato) por uma fase vítrea previamente obtida (fluxo), tem-se mostrado possível, principalmente devido aos baixos valores de absorção de água, em temperaturas de queima mais baixas do que aquelas utilizadas nas composições tradicionais. Esses fatores, aliados a uma menor retração linear de queima e bons resultados referentes à resistência mecânica à flexão, tornam a substituição um fator de interesse para estudos mais aprofundados, por exemplo, com relação à deformação e também no que se refere a viabilidade econômica.

\section{AGRADECIMENTOS}

Os autores expressam seus agradecimentos à Fundação de Amparo à Pesquisa - FAPESP pelo apoio financeiro.

\section{REFERÊNCIAS}

[1] J. O. A. Paschoal, A. P. M. Menegazzo, "Mercado Nacional e Mundial de Grês Porcelanato", Cerâmica Informação 18 (2001) 25-33.

[2] E. Sánchez, "Considerações Técnicas sobre Produtos de Revestimento Porcelanato e Seus Processos de Manufatura. Parte 1", Cerâmica Industrial 8, 2 (2003) 7-16.

[3] R. T. Zauberas, A. O. Boschi et al., "Processamento $x$ Propriedades de Grês Porcelanato", Cerâmica Industrial 8, 3 (2003) 13-16.

[4] A. P. M. Menegazzo al. "Grês Porcelanato. Parte I: Uma Abordagem Mercadológica", Cerâmica Industrial 5, 5 (2000) 8-10.

[5] F. J. S. Arantes et al. "O Manchamento e a Porosidade Fechada de Grês Porcelanato", Cerâmica Industrial 6, 3 (2001) 18-25.

(Rec. 01/07/2005, Rev. 12/01/2005, Ac. 03/06/2005) 